\title{
Ah
}

\section{Diodoro de Sicilia y la historia universal}

\author{
[Diodorus Siculus and the Universal History]
}

\author{
Héctor A. Vega Rodríguez \\ (Universidad Nacional Autónoma de México) \\ hvegar@comunidad.unam.mx
}

\begin{abstract}
Resumen:
En este trabajo propongo un análisis de los elementos que integran la Biblioteca Histórica de Diodoro de Sicilia y que permiten entender el texto como una obra de historia universal. Expongo un recorrido por la historia y particularidades del género historiográfico para situar la obra como parte de una tradición literaria con un modelo propio, pero que a su vez presenta elementos específicos en cada uno de sus exponentes.

Palabras clave: Diodoro - Historia Universal

- Historiografía Helenística - Sucesión de Imperios - Benefactores
\end{abstract}

\begin{abstract}
:
In this paper I propose an analysis of the elements that constitute Diodorus's Library of History that will allow us to understand the text as a work of universal history. I expose a journey through the history and peculiarities of the historiographical genre to situate the work as part of a literary tradition with its own model, but which presents at the same time specific elements in each of its exponents.
\end{abstract}

Keywords: Diodorus - Universal History Hellenistic Historiography - The Succession of Empires - Benefactors

Recibido: 29/11/2018

Evaluación: 15/3/2019

Aceptado: 14/6/2019

Anuario de la Escuela de Historia Virtual - Año 10 - N 15 - 2019: pp. 1-26.

ISSN: 1853-7049

http://revistas.unc.edu.ar/index.php/anuariohistoria 


\section{Diodoro de Sicilia y la historia universal}

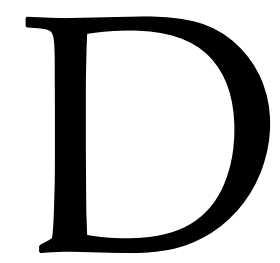

iodoro de Sicilia vivió tiempos turbulentos. El historiador originario de Agirio es el autor de una de las obras de historia más extensas de la antigüedad. Su Biblioteca Histórica estuvo conformada por cuarenta libros y en ella se narra la historia del mundo conocido desde antes de la guerra de Troya hasta el presente del autor, pasando por la descripción de los mitos de griegos y bárbaros y la explicación histórica de los hechos acontecidos en Roma, Grecia, Sicilia y las áreas circundantes. Testigo del fin de la república romana, Diodoro vivió gran parte del siglo I a.C. ${ }^{1}$ Si bien los datos exactos sobre su fecha de nacimiento y muerte no se conocen, la lectura de su obra, y la información que en ella refiere de sí mismo, nos permite ubicar la escritura de su Biblioteca en la segunda mitad de dicho siglo. Las condiciones históricas que rodean la escritura de su texto son razón suficiente para interesarse en su lectura y análisis. Además, la universalidad espacio-temporal que pretende Diodoro, convierten a su obra en una fuente vasta de información y en un vínculo con la literatura perdida, la cual sirvió como fuente para su texto.

Una de las principales discusiones en torno a su obra radica en la originalidad de la misma y en el papel que Diodoro tuvo como copista o como creador de un discurso histórico coherente. Los términos de esta discusión historiográfica rebasan el objetivo de este trabajo. ${ }^{2}$ Sin embargo, me interesa invitar al lector a reflexionar sobre los elementos contenidos en la obra que la convierten en un objeto de estudio relevante y en un autor con una perspectiva diferente respecto a sus contemporáneos. El tema que propongo abordar responde precisamente a una de las características que convierten a la Biblioteca Histórica en una obra historiográfica de gran valía.

El objetivo de la presente investigación es analizar la perspectiva universal de la Biblioteca Histórica como producto de una serie de condiciones materiales e intelectuales en las que estuvo inserto Diodoro. Busco exponer de manera somera un recorrido por las características del género historiográfico con el fin de situar la obra como parte de una tradición literaria con un modelo propio, pero con particularidades en cada uno de

\footnotetext{
${ }^{1}$ Todas las fechas son antes de Cristo a menos que se indique lo contrario.

${ }^{2}$ La discusión sobre la originalidad de la obra de Diodoro ha provocado un importante número de estudios. Inserto este trabajo en una corriente revisionista en contra de la postura tradicional respecto al estudio de la obra del historiador siciliano. La Biblioteca, al ser analizada para tratar de identificar en ella extractos de autores griegos hoy perdidos, perdió su importancia como obra de historia en sí misma. Esta postura revisionista sostiene que en las secciones no narrativas de la obra pueden identificarse elementos de autoría de Diodoro. Tal es el caso de los proemios, discursos y en pasajes donde el autor busca polemizar con otros. Estos elementos presentes en la historiografía griega en general reaparecen en Diodoro y en ellos se ha basado gran parte de la corriente que lo revalida como autor original cuyos postulados metodológicos e ideales políticos y morales se plasman en su obra. Entre los autores que han formulado y defendido esta postura destacan: Farrington (1947), Palm (1955), Sacks, (1981, 1990), Rubincam (1985, 1987, 1989, 1998a, 1998b), Clarke (1999), Bosworth (2003), Green (2006), Sheridan (2010), Sulimani (2011) y Muntz (2017).
} 
sus exponentes. Del mismo modo pretendo, por un lado, explicar las características que integran la obra de Diodoro y que la convierten en un texto de historia universal; por otro lado, profundizar en torno a las problemáticas que se desprenden del género de la historia universal en Diodoro como son: la sucesión de los imperios, el papel de Roma en el ámbito universal, la composición y estructura de la obra, y la influencia del estoicismo en el autor.

\section{Origen y desarrollo de la historia universal. El lugar de Diodoro de Sicilia}

Es importante partir de un problema de definición. La historia universal puede ser entendida desde distintas perspectivas. Hace algunos años, Liddel y Fear editaron un texto titulado Historiae Mundi. Studies in universal history (2010), en el cual presentan las distintas formas de acercarse al problema de la universalidad en la historia desde la antigüedad griega hasta el siglo XIX europeo. Como ellos, inicio la exposición de este apartado con un intento de definir el concepto de historia universal y el origen u orígenes de la misma. Dada las características de este trabajo, me limitaré a abordar aquellos aspectos útiles para mi explicación de la obra de Diodoro, por lo cual no pretendo ser exhaustivo al respecto.

El historiador universal en el mundo griego era aquel que "estudiaba la historia de la humanidad desde los tiempos más remotos y en todas las partes del mundo conocido" (Alonso-Núñez, 2002, p. 117). Esta primera definición presenta algunos problemas por la incapacidad de aplicarla al conjunto de historiadores griegos que hoy consideramos que abordaron la historia desde una mirada universal. Debemos observar el valor universalista que los mismos autores antiguos dieron a sus obras. Desde el trabajo de Heródoto -quien afirma ocuparse de hechos tanto de griegos como de bárbaros (Hdt. 1.1.1.) y concibe un devenir histórico que incluye a pequeñas y grandes ciudades y a distintos pueblos, dado que el bienestar humano no es permanente (Hdt. 1.5.3-4)-, podemos afirmar que la historia como género literario nace con una perspectiva universalista enfocada en los procesos de cambio. ${ }^{3}$ Así, tanto Heródoto, como Polibio, Pompeyo Trogo y, por supuesto, Diodoro, entre los autores cuyas obras se conservan lo suficiente como para tener una idea clara de su contenido, proponen una perspectiva universal de la historia. Sin embargo, la diferencia descansa en el proceso, lugar u objeto en el cual encuentran dicha universalidad.

El historiador universal buscaba generar un estudio en el que se abordaran de manera más amplia los hechos acontecidos en el mundo conocido contenidos en un solo texto. (D. S. 1.1.2-4; 3.1-4). De entrada, el problema estriba en definir si la universalidad histórica dependía del tratamiento de "todo" el tiempo en "todo" el espacio, o si uno de estos elementos era suficiente para ofrecer una mirada más amplia que aquella contenida

\footnotetext{
${ }^{3}$ Momigliano (1993). En este artículo, el autor enfatiza la importancia que para los historiadores griegos tuvo estudiar los fenómenos de cambio relevantes para la vida dentro de la polis.
} 
en las historias locales. ${ }^{4}$ Los trabajos de historia universal tendieron a fijar su mirada en el Mediterráneo grecorromano, mientras que la periferia bárbara fue tratada, conscientemente, como marginal y no ocupaba un lugar predilecto en la narración (Cornell, Fear y Liddel, 2010, p. 1). A partir de lo anterior, la historia universal puede presentarse como un devenir cíclico, lineal y/o progresivo, invariablemente con su centro de gravedad en la cultura griega y/o romana. Dada la inviabilidad consciente de los historiadores antiguos de escribir una narración de todo lo acontecido en todos los lugares en todo el tiempo, ${ }^{5}$ el criterio de selección de fuentes, junto con la necesidad de fijar una postura respecto a la noción de universalismo parecen necesarias en los autores. Esto resultó en la necesidad de justificar su postura respecto a por qué consideraron a su trabajo como una obra de historia universal. De ahí que Marincola (2007, p. 171) haya identificado dos tipos: aquellas universales en tiempo y espacio (como la de Diodoro) y las universales solo en espacio (como la de Polibio). Por lo tanto, también se hizo necesario establecer esquemas de explicación histórica aplicables a la universalidad (Cornell, Fear y Liddel, 2010, p. 2). Los cambios en las constituciones, la sucesión de imperios, el desarrollo progresivo de la humanidad, entre otros, aparecen como ejes sobre los cuales se observa la condición universal en la historia.

Parece claro que el origen mismo del género histórico en el siglo $\mathrm{V}$ va de la mano del enfrentamiento producto del contacto entre el mundo griego y los bárbaros. ${ }^{6}$ La búsqueda de identidad griega quedó ligada al discurso sobre los "otros" contenido en las obras de historia desde el texto de Heródoto. El enfrentamiento entre dos pueblos y el resultante dominio de uno sobre el otro puso en perspectiva universal la historia de ambos, pues, colocó en el centro al vencedor y la historia del vencido quedó subordinada al desarrollo del primero. En Polibio es muy claro. El dominio romano sobre el Mediterráneo sirvió de amalgama para unir las historias de los pueblos vencidos y posibilitó, hasta ese momento y no antes, una visión universal de la historia (Plb. 1.1.5; 3.1-10). ${ }^{7}$ De lo anterior se desprende que la historia universal no solo dependa de un marco temporal para desarrollarse, sino de un vínculo que ligue los temas locales en un desarrollo general único y a veces, unidireccional. Este vínculo depende de la propuesta del autor.

Si bien he señalado que en Heródoto pueden encontrarse los inicios de una perspectiva universal, es necesario plantear un par de interrogantes. Primero, ¿cuándo surge el género de la historia universal como una narración consciente y apartada del devenir histórico local o de un solo pueblo? Y, en segundo lugar, ¿en qué coyunturas específicas encontramos una exposición universal de la historia? Los estudiosos modernos coinciden en ubicar el nacimiento del género en el siglo IV, en particular con

\footnotetext{
${ }^{4}$ Cf. Clarke (2008, pp. 90-168).

${ }^{5}$ Por ejemplo, Plb. 1.5.2-5.

${ }^{6}$ Cf. Martínez Lacy (2004, pp. 25-44).

7 Para Polibio la Paz de Naupacto del 217 es el punto de inicio del entretejimiento de la historia universal (5.105.4-10).
} 
la obra de Éforo (ca. 400-330) (Marincola, 2007, pp. 172-74). Entre los exponentes de este podemos mencionar a Teopompo, Polibio, Posidonio, Nicolás de Damasco, Diodoro, Pompeyo Trogo, Timágenes e incluso Estrabón, entre los más importantes. Sin embargo, el análisis puntual de sus obras revela perspectivas distintas y no una estandarización u homogeneización de la forma o contenido del género. Más allá de si parten de una visión universal temporal/espacial o solo espacial, las divergencias observadas son más profundas y responden a los intereses personales de cada uno, su objetivo principal y la realidad histórica en la que están insertos.

En el siglo V y como bien apuntó Clarke (2008, p. 90), Tucídides integró en su discurso acontecimientos significativos para habitantes de más de una polis al momento de usar marcas cronológicas distintas a las de Esparta y Atenas (Th. 2.2.1). El sincronismo empleado le permitió vincular hechos acontecidos en distintas latitudes por medio de las distintas cronologías, algo esencial para los posteriores historiadores. Aunque más adelante se muestra inconforme con la datación cronológica a partir de los arcontados epónimos (Th. 5.20), Tucídides parece consciente de un problema que después ocupará a los historiadores universales, entre ellos Diodoro. La ruptura entre la historia local y la perspectiva universal se encuentra en el siguiente siglo y se desarrolló durante el período helenístico. A continuación, presento un sintético desarrollo del problema que me permitirá proponer una solución a los interrogantes planteados arriba.

Para diferenciar el texto de Diodoro del resto de los autores que afirman escribir una historia universal, me limitaré a hacer los siguientes señalamientos. La Biblioteca Histórica forma parte de una tradición historiográfica, la misma que tiene sus orígenes en el texto de Éforo y que la vincula con una serie de autores que escribieron historia universal. Las Historias de Éforo en treinta libros abarcaron del retorno de los Heráclidas al reinado de Filipo II de Macedonia (en particular el asedio de Perinto del 338). Según Polibio, fue el primero en intentar una historia general (Plb. 5.33.2). Diodoro mismo alaba la forma de arreglar la información disponible en el texto de Éforo. Preocupado constantemente por una buena disposición orgánica de su texto en cuanto a la distribución del material, el siciliano señala que fue un acierto de parte de Éforo el que "cada uno de sus libros contenga hechos elegidos por el criterio de afinidad" (D. S. 5.1.4). Es decir, acomodó eventos comunes de acuerdo con el área geográfica y no siguiendo una tradición fijada en la cronología, motivo por el cual critica a Timeo en el mismo pasaje (5.1.3). Diodoro retomará esta postura de Éforo y organizará su material de acuerdo con una buena economía con el afán de hacerlo más comprensible y observar, en un mismo libro, el desarrollo y desenvolvimiento de un evento hasta su fin. De ahí puede desprenderse la inclusión de proemios en cada uno de sus libros (excepto en II, III y XI) con la idea de generar una lectura más agradable, útil y coherente como prometió al inicio.

Éforo vinculó los hechos de todos los griegos al momento de señalar que la victoria de Gelón sobre Cartago, acaecida en tiempos de las guerras médicas, "liberó no solo a Sicilia sino a toda Grecia" (FGrHist 70 F 186). Así, observamos que la universalidad en 
Éforo descansa en el vínculo de las historias locales griegas con respecto a un solo propósito. No es gratuito que siglos más adelante Justino, quien epitomiza las Historias Filípicas de Pompeyo Trogo, siga alimentando la idea de que la batalla de Himera, en donde los cartagineses fueron detenidos por Gelón, haya acontecido el mismo día en que los ejércitos griegos detuvieron el avance de Jerjes en Salamina (Just., Epit. 19.1.10). ${ }^{8}$ La autodefinición del mundo griego en los siglos V y IV a partir del contraste con los bárbaros provocó la necesidad de plantearse problemas inherentes al desarrollo del mundo griego fuera de la polis y, en consecuencia, sobre los hechos de los bárbaros.

Diodoro apuntó que Éforo pasó por alto los relatos de la antigua mitología, ya que tomó como punto de partida en su obra el retorno de los Heráclidas, al igual que Teopompo y Calístenes (5.1.3). Si consideramos la distinción entre el tiempo mítico y el histórico (humano) como condición del ejercicio de la historia (Martínez Lacy, 2004, pp. 41-42), la obra de Éforo cumple con dicho elemento, mientras que Diodoro, al incluir la narración de mitos se separaría de esta corriente de autores de historia universal. Sin embargo, la inclusión de mitos cumple una función, la cual no está alejada del objetivo de la historia. ${ }^{9}$ Lo que observamos es el acercamiento distinto que cada autor propuso respecto al tiempo mítico. Por ejemplo, Heródoto considera a Polícrates de Samos como el primero que aspiró a conseguir la hegemonía marítima en la época humana (Hdt. 3.122.2), excluyendo a Minos, a quien incluye dentro del tiempo mítico; Tucídides, en cambio, ve a la talasocracia de Minos como un fenómeno histórico (Th. 1.4). Para la historia universal, el punto de partida cambia y se remonta considerablemente en el tiempo. Éforo, Teopompo y Calístenes parten del regreso de los Heráclidas, como punto de quiebre entre el tiempo mítico y el histórico, o bien el heroico y el humano (Schepens, 1977, p. 107). El problema que evidentemente surge de este razonamiento es que la antigua confianza depositada por los historiadores en el testimonio ocular ya no es suficiente para cubrir la cantidad de años contenidos en las historias universales, ya sea la de Éforo o la de Diodoro. Por ello, se vuelve necesaria la consulta cada vez mayor de literatura anterior como fuente (Clarke, 2008, p. 101; Schepens, 1977, pp. 104-105). Incluso más cuando el texto de Diodoro comprende, según sus propias cuentas, 1138 años (1.5.1).

Con la obra de Éforo, la perspectiva universal de la historia tuvo que enfrentarse al problema de cómo tratar tanto material empleado en la investigación y cómo acomodarlo. El conflicto más grande fue la relación espacio-temporal, pues, sin duda, una debió tener mayor peso que la otra al momento de organizar el material para presentarlo. Si seguimos a Clarke, Éforo solucionó el problema al tomar el material obtenido de historias locales y ordenarlo en una perspectiva universal cronológicamente (olimpiadas), lo que le permitió dar saltos espaciales. (Clarke, 2008, p. 102). En Diodoro encontramos otra solución, que será analizada más adelante.

\footnotetext{
${ }^{8}$ Ya Heródoto había planteado esta coincidencia en 7.166. Diodoro habla de una alianza persa-cartaginesa en 11.20.1, aunque sitúa la batalla de Himera como simultánea a la de las Termópilas, no a Salamina 11.24.1 ${ }^{9}$ Cf. Sulimani (2011).
} 
Al igual que Éforo, Teopompo de Quíos (ca. 378-320) escribió una obra de historia universal. En ella trató los hechos de griegos y bárbaros hasta sus propios días. Esto vincula en mayor grado la obra de Diodoro con la de Teopompo, más que con la de Éforo. En su obra, además de lo acontecido entre griegos y bárbaros, Teopompo (al igual que Diodoro) incluye la narración de acontecimientos maravillosos o extraordinarios. Parece ser que el elemento sobre el cual gira la construcción de la universalidad de la historia es Filipo II, quien con sus conquistas unificó las historias de varios pueblos (Bruce, 1970). Incluso Polibio lo critica por fallar en su objetivo de enlazar su Historia de Grecia donde la dejó Tucídides, pues al llegar a la batalla de Leuctra modifica sus planes y funde la historia en las gestas de Filipo; es decir, una historia centrada en un rey (Plb. 8.11.3). ${ }^{10}$

De los párrafos anteriores obtenemos datos interesantes para analizar. Tanto Éforo como Teopompo vivieron en el siglo IV. Ambos fueron testigos del desarrollo histórico de la segunda mitad del siglo que llevó a Macedonia, bajo el mandato de Filipo II, al control del mundo griego. Esta perspectiva de cambio se posicionó como tema de los historiadores de su tiempo, quienes en su análisis vincularon los hechos en una sola narración y, más importante aún, en un solo devenir histórico. Del mismo modo, la obra de Diodoro está ubicada en una coyuntura histórica específica, caracterizada por el control romano sobre el Mediterráneo, su expansión hacia los territorios galos y el mundo griego, incluida su natal Sicilia. Por lo tanto, parece clara la relación entre las condiciones históricas que rodean la escritura de textos de historia universal y la perspectiva histórica contenida en ellos. No es gratuito que el género haya sido desarrollado por Éforo y Teopompo en el momento del ascenso macedónico, o que otros exponentes como Calístenes, Posidonio, Polibio, Agatárquides y Timágenes hayan vivido en el período helenístico, durante el cual el cambio de perspectiva fue evidente y la realidad histórica acontecida tras las conquistas de Alejandro provocó la creación de nuevos géneros literarios. ${ }^{11}$ Más aun, el propio Diodoro, Nicolás de Damasco y Estrabón se ubican dentro de los últimos años de la república romana y el principado de Augusto, el último incluso hasta el gobierno de Tiberio, ${ }^{12}$ momentos importantes de cambio que no pudieron pasar desapercibidos a los historiadores del momento. El reinado de Filipo II y la posterior campaña de Alejandro llevó por un nuevo rumbo a la historia griega, rumbo que solo puede abordarse desde la historia universal; del mismo modo, el principado de Augusto selló la hegemonía romana sobre el Mediterráneo, hegemonía que solo puede entenderse desde la universalidad. Fue similar lo que sucedió siglos después cuando el cristianismo se consolidó como la religión dominante, en ese sentido,

\footnotetext{
${ }^{10}$ Cf. Moreno Leoni (2017, pp. 47-48). El autor ve en la crítica a Teopompo una lectura más del etnocentrismo de Polibio.

${ }^{11}$ Gómez Espelosín $(2006 ; 2010)$.

${ }^{12}$ Para Alonso-Núñez (2002, p. 96), la época de Augusto vivió el florecimiento de la historia universal, no su origen.
} 
las Historias de Paulo Orosio son un claro ejemplo del universalismo abordado desde el providencialismo agustiniano.

No podemos hablar de la universalidad de la historia sin abordar el caso de Polibio. No es motivo del presente trabajo profundizar en la obra del historiador megalopolitano, sin embargo, dado que es considerado una de las fuentes principales de Diodoro y, sobre todo, alguien de quien según algunos autores "copió" la información,13 hay que hacer los siguientes apuntes. Para Polibio la mejor educación era obtenida de la historia política (universal), pues ella es la única que, "sin causar prejuicio, produce en toda situación y circunstancia jueces correctos de lo mejor" (Plb. 1.35.9-10). Diodoro afirma lo mismo, de hecho, con esto inicia su obra (1.1.1). Sin embargo, parece ser que en la utilidad de la historia universal terminan las coincidencias entre ambos autores. Diodoro mismo alaba la labor del historiador universal y pone como requisito que este llegue hasta sus propios días. Polibio narra lo vivido por él (aunque esta parte de la obra haya sido transmitida en estado fragmentario). Sin embargo, esta línea de razonamiento no puede llevarnos a la conclusión de que la noción de universalidad de la historia en Diodoro sea un calco de la postura de Polibio. Para él, la universalidad descansa en el poder romano sobre el Mediterráneo a partir del cual se entretejen los eventos y todos apuntan a un mismo fin (Plb. 1.3.4);14 mientras que, para Diodoro (1.3.2-6), la misma depende de tratar los temas de todos los pueblos en todos los tiempos, como si se tratara de los de una sola ciudad.

Como apuntó Sheridan, tanto Polibio como Diodoro proceden a explicar por qué su obra en particular será mejor que las de sus predecesores (Sheridan, 2010, pp. 45-46). Más que criticarlos, Diodoro parte de los autores anteriores con el objetivo de "mejorar" sus obras (1.3.8.) al incluir, bajo un hilo de continuidad, todos los eventos acontecidos en todo el mundo conocido en un solo relato, generando así con su obra un aporte útil. ${ }^{15}$ Tanto Polibio como Diodoro coinciden en que Éforo fue el primer historiador universal (o al menos el primero en intentar serlo) (Plb. 5.33.2; D.S. 5.1.4). Polibio inicia su obra en el año 264 (inicio de la Primera Guerra Púnica y fin de la obra de Timeo de Tauromenio). ${ }^{16}$ A partir de este punto los sucesos se entrelazan y apuntan a un mismo fin. El objetivo planteado por el historiador: "conocer cómo y por qué genero de constitución política fue derrotado casi todo el universo en cincuenta y tres años no cumplidos, y cayó bajo el imperio indisputado de los romanos" (Plb. 1.1.5), definió su perspectiva universalista. De ahí lo innecesario de abordar las "causas de las causas"

\footnotetext{
${ }^{13}$ Hornblower (1981, pp. 25-26); Stylianou (1998, p. 23). En contra de esta postura: Sheridan (2010, pp. 4151).

${ }^{14}$ Hartog (2010, pp. 30-40) usa este pasaje como argumento para hablar de una "primer historia universal." Sheridan (2010, pp. 46-48) señala en cambio que la idea de universalidad en Polibio es menos clara y que lucha cuando trata de explicar lo que para el significa la historia universal.

${ }^{15}$ La crítica de los historiadores a sus predecesores era común entre los historiadores de la antigüedad. Cf. Walbank (1962: 217ss.); Marincola (1997); Martínez Lacy (2004). Baste ver como ejemplos: Th. 1.22.4; Plb. $1.14-16,2.56,3.21-23,12.4-28$.

${ }^{16}$ Los dos primeros libros de Polibio eran considerados por el mismo su introducción, por lo tanto, la obra propiamente dicha inicia en el libro III con el relato de la guerra contra Aníbal.
} 
(Plb. 1.5.2-5) y remitirse al pasado más remoto. Por otro lado, Diodoro no comparte el objetivo de Polibio. Para él, mientras más lejos se encuentre el punto de inicio de la narración, más benéfico será el trabajo (D.S. 1.3.2), algo por cierto nunca intentado antes. Para Diodoro, las Historias de Polibio no dejan de narrar hechos aislados. El haberlas consultado como fuente, no determina la comunión con sus ideas o perspectivas.

\section{La sucesión de los imperios y el lugar de Roma en la historia universal}

Me parece necesario hacer algunos apuntes sobre la sucesión de los imperios como tema de la historia universal. Desde el clásico artículo de Trieber (1892), quien atribuye un origen griego a esta teoría, posible solo tras la batalla de Magnesia como probable punto de quiebre en donde Roma puede posicionarse como el nuevo poder hegemónico, la bibliografía ha crecido considerablemente. ${ }^{17}$ Como señaló Momigliano, a la teoría de la sucesión de los imperios le antecedió en el pensamiento griego el esquema de la sucesión de razas; el esquema biológico, según el cual individuos y naciones pasan por las fases de la niñez, la juventud, la madurez y la vejez; y el esquema del progreso de la humanidad desde la barbarie hasta la civilización (Momigliano, 1984, p. 266). Bajo este razonamiento, Momigliano encuentra en Hesíodo al primer exponente de un esquema universal (no histórico). En el avance progresivo de la humanidad, existen individuos, dioses o héroes culturales que sirven como benefactores para incentivar dicho avance o para revelar conocimientos tecnológicos. El Prometeo de Esquilo parece ser un ejemplo paradigmático. En el primer libro de la Biblioteca Histórica, se defiende el papel que estos benefactores han tenido y más aún, se considera al historiador (universal), y al mismo Diodoro, como uno de ellos. Puedo argumentar que este punto es un factor que Diodoro consideró esencial en una obra de historia universal, de ahí la inclusión de mitos en su narración, pues en ellos podía encontrar héroes benefactores.

Para el final del período republicano en Roma, el sistema de organización cronológica de acuerdo con la sucesión de los imperios hegemónicos estaba ampliamente desarrollado y aceptado. La línea sucesoria de asirios-medos-persas-macedonios y la posibilidad de incluir a Roma como el quinto imperio sirvió como esquema organizativo del material abundante propio de las historias universales. En el mundo griego, aparentemente el primero en hacer uso de este modelo fue Ctesias, ${ }^{18}$ mientras que, en el

\footnotetext{
${ }^{17}$ Después de Trieber, el artículo de Swain (1940) provocó un intenso debate historiográfico sobre el origen griego u oriental del esquema de organización por imperios. En términos generales autores como Alonso Núñez (2002); Mendels (1981); Flusser (1972) y Momigliano (1982) han explicado y defendido el modelo como forma organizativa del relato historiográfico universal. Del mismo modo se han publicado textos que aterrizan el problema al análisis de casos particulares como el de Burstein (1989), Parmentier y Barone (2011); Alonso Núñez (1992); Engels (2010). Hay que agregar que ha habido voces que han puesto en tela de juicio la relevancia del esquema como modelo de organización de contenidos, en ese sentido Engels (2010, p. 74) minimiza el rol del mismo, a diferencia de la relevancia que le otorga Alonso Núñez (1992; 2002).

${ }^{18}$ Sobre Ctesias: Lenfant (2007). Su uso en Diodoro (Muntz, 2017, pp. 23-26). Según Llewelyn-Jones y Robson (2010) el uso que Diodoro hace de Ctesias es crítico, pues no se limita a copiarlo, sino a complementar lo expuesto por él. En ese mismo sentido: Bigwood (1980, pp. 195-207). Todo apunta a que Ctesias fue la principal fuente para gran parte del libro II de Diodoro.
} 
mundo romano, un pasaje conservado en Veleyo Patérculo (1.6.6) apunta al conocimiento del esquema por Emilio Sura. Según Swain (1940) esto reflejaría el origen oriental del modelo y la apropiación romana del mismo para la segunda mitad del siglo II, a diferencia de lo defendido por Trieber. Momigliano (1982), Alonso Núñez (1989) y Kramer (2005) apoyan la postura del primero.

La teoría de la sucesión de los imperios es un tema tratado constantemente en la tradición historiográfica griega. Heródoto apuntó a la relevancia de los medos como sucesores de los asirios (Hdt. 1.102.2), quienes gobernaron Asia por más de quinientos años (Hdt. 1.95.2). Según Muntz (2017, pp. 36-46), este esquema penetró el pensamiento romano y dibujó una línea sucesiva de autores que notaron el problema y lo incluyeron como modelo para componer sus obras entre los cuales ubica a Ctesias, Agatárquides, ${ }^{19}$ Emilio Sura, Dionisio de Halicarnaso, Pompeyo Trogo ${ }^{20}$ y Nicolás de Damasco. ${ }^{21}$ Si bien en todos ellos se observan diferencias, algunas de las similitudes anotadas son la importancia dada a Asiria como el primer imperio y la sucesión progresiva de Estados que lo relevaron.

Polibio parece separarse de esta postura. La sucesión de los imperios en las Historias se evidencia cuando compara el desarrollo de los reinos antiguos más importantes con Roma:

En cierta época los persas consiguieron un gran reino, un gran imperio, pero siempre que se arriesgaron a cruzar los límites de Asia pusieron en peligro no solo este imperio, sino sus propias vidas. Los lacedemonios pugnaron largo tiempo para hacerse con la hegemonía sobre los griegos, y cuando, al fin, la consiguieron, lograron conservarla indiscutidamente doce años escasos. Los macedonios dominaron Europa desde las orillas del Adriático hasta el río Danubio, lo que, en su totalidad, parecería una pequeña parte del territorio aludido. Pero posteriormente, aniquilaron al poderío persa y se anexionaron el imperio de Asia. Sin embargo, aunque dieron la impresión de que se habían apoderado de muchas más regiones y estados, dejaron la mayor parte del universo en poder de otros, porque no se lanzaron nunca a disputar el dominio de Sicilia, ni el de Cerdeña, ni el de África y en cuanto a los pueblos occidentales de Europa, belicosísimos, digámoslo escuetamente: ni siquiera los conocieron. En cambio, los romanos sometieron a su obediencia, no algunas partes del mundo, sino a éste prácticamente íntegro (Plb. 1.2.2-7).

Este triunfo de Roma fue el tema central del texto de Polibio. El mismo devenir histórico romano apuntaba, si seguimos a Apiano (Pun. 132) a un declive futuro. ${ }^{22}$ Polibio vincula los acontecimientos históricos en función del ascenso y consolidación de Roma como la potencia del Mediterráneo. Es claro que para el momento en que Diodoro escribe, la teoría de la sucesión de los imperios era ampliamente conocida (Muntz, 2017,

\footnotetext{
19 Para Agatárquides, ver: Burstein (1989).

${ }^{20}$ Es fundamental el texto de Alonso Núñez (1992).

${ }^{21}$ Para el esquema en Nicolas de Damasco, ver: Parmentier y Barone (2011).

${ }^{22}$ Es importante notar que Walbank (1979, p. 722) considera que las famosas palabras de Escipión en referencia a la futura caída de Roma no estaban incluidas en el texto de Polibio, sino que son agregadas por Apiano.
} 
p. 39). En las Antigüedades romanas, Dionisio de Halicarnaso (Ant. Rom. 1.2.1-4) ve a Roma no solo como el último de los imperios en la línea sucesoria, sino también como al más grande, esplendoroso y duradero. En las Historias Filípicas de Trogo se toma la secuencia de sucesión de los imperios como modelo organizativo. ${ }^{23}$ Dicha secuencia inicia con los asirios (Just., Epit. 1.2.13), quienes lo transfirieron a los medos (1.3.6) y estos a los persas (1.6.17). Posteriormente, en un autor cristiano como Orosio, la historia de la decadencia de Roma en función de la existencia de un nuevo y eterno imperio cerraría el círculo iniciado con Babilonia y sucedido por Cartago y Macedonia (Oros. 5.1-3). Si a esta tradición sumamos los agregados obtenidos de la tradición judía, la cual, como señaló Momigliano "sobrepujaron a los griegos sacando el relato del presente para llevarlo al futuro" (Momigliano, 1984, p. 265), ambas convergen en el discurso sobre la sucesión de los imperios. Tanto en Los trabajos y los días (Hes., Op. 107-202), como en las Historias herodoteas (Hdt. 1.95) puede plantearse la existencia de una sucesión de imperios que, en Polibio, como ya vimos, se encuentra desarrollada. Del lado judío, en el libro de Daniel aparece la promesa del Juicio (Dn. 10-12) y la sucesión de imperios que precederá al reino eterno de Dios (Dn. 7-8). Basten los ejemplos anteriores para defender la idea anotada por Alonso-Núnez de que el esquema y teoría de la sucesión de los imperios es indispensable en las obras de historia universal (Alonso-Núñez, 2002, pp. 100-101). Con esto en mente, parece sólida la idea defendida por Vlassopoulos (2007: 20-22), quien afirma que el esquema trascendió el espectro temporal del imperio romano. En este sentido, dicha problemática aparece también en la Biblioteca Histórica de Diodoro.

En el ambiente de las guerras del último siglo antes de Cristo, parece pertinente plantearse de nuevo la problemática sobre la sucesión de los imperios. Los autores que retomaron este asunto fueron Posidonio, Estrabón, Nicolás de Damasco y Diodoro y, en el caso latino, Pompeyo Trogo. ${ }^{24}$ Todos ellos, por cierto, son originarios del mundo provincial. Según Momigliano, estos autores trataron de oponer cierta resistencia a una visión de la historia mundial que era una forma de glorificar a Roma y en consecuencia concedieron un importante papel a las civilizaciones antiguas de Oriente y a Grecia y enfatizaron la relativa barbarie romana y su reciente conversión a las costumbres griegas (Momigliano, 1984, p. 279). Muntz (2017, pp. 44-46) opina similarmente al afirmar que, al menos en el caso de Diodoro, el énfasis puesto en la importancia de otras naciones (Egipto, Persia, Arabia, Babilonia), y la narración no lineal que rompe la transición entre imperios parece ofrecer una perspectiva distinta, la cual no culmina con Roma como última en la línea sucesoria. A lo anterior hay que agregar que la obra de Diodoro inicia no con la relación de los hechos de Asiria, sino con los de Egipto y en el libro II rompe la narración de los reyes de Media y Persia para tratar los hechos de la India, Escitia, Arabia y el viaje de Yámbulo a las islas del Sol (2.35-60). Diodoro propone una teoría de la sucesión de los imperios distinta en donde incluir a Roma y, sobre todo, que está

\footnotetext{
${ }^{23}$ Cf. Alonso-Núñez (1987); Martínez Lacy (2005).

${ }^{24}$ Para un análisis puntal del texto de Trogo epitomizado por Justino, ver: Alonso-Núñez (1987).
} 
relacionada con la función moralizante de su obra. Expongo este punto a continuación como elemento que forma parte de su noción de historia universal.

Vale la pena detenerse a analizar la postura de Diodoro respecto al dominio romano. El aparente "aislamiento" intelectual del historiador de Agirio no lo hizo indiferente a lo ocurrido en Roma y, a lo largo de su obra, se evidencia la importancia que le da al desarrollo de los hechos protagonizados por la ciudad. ${ }^{25}$ El vínculo establecido entre la aristocracia romana y los intelectuales griegos provocó que la mayoría de estos tuvieran una opinión positiva de Roma. El afecto y adulación hacia ella "era casi universal" (Sacks, 1990, p. 190). Gabba (1984, pp. 61-63) enfatiza el elogio a Roma por parte de los historiadores contemporáneos. Si bien Diodoro no es abiertamente crítico del dominio romano, sí subordina el papel de Roma en su Biblioteca a su mayor objetivo, la función moralizante de la historia. Dentro de esta perspectiva, condena actitudes de Roma, sobre todo, cuando, una vez dominado gran parte del mundo, dejaron de ser moderados o beneficiosos hacia sus súbditos. Diodoro se preocupó por evidenciar los actos bondadosos y viles de los hombres, en donde estos últimos provocaron el declive de ciudades e imperios. En este sentido, Roma será juzgada del mismo modo y en ella Diodoro encontrará tanto benefactores como prácticas dignas de condena.

Como observó Sheridan (2010, p. 50), la perspectiva universal de la historia permitió a Diodoro ubicar a Roma en un contexto más amplio. Desde esta mirada, Roma es abordada no desde la adulación a la ciudad, a su ascenso o a sus líderes, sino desde la perspectiva moralizante que le permitió a Diodoro aplaudir y condenar las decisiones tomadas y las acciones emprendidas. Si, como apuntó Alonso-Núñez (2002, p. 164), el período de Augusto vio florecer la historia universal, en ella el desarrollo histórico de Roma forzosamente debió ser incluido.

\footnotetext{
25 Trabajos como el de Rawson (1985) y, más recientemente, Yarrow (2006), han problematizado sobre la vida intelectual griega en los últimos años de la República romana. Durante el primer siglo a.C. hubo un flujo importante de actividad intelectual griega en Roma, acompañada de la intención de buscar fuentes de información y/o el apoyo de la aristocracia romana, la cual, según Rawson (1985, p. 105), tomó el lugar de los reyes helenísticos como patrones de los intelectuales griegos. Muchos de los griegos que llegaron a Roma durante ese siglo estuvieron ligados a alguna de las familias romanas más prominentes (Yarrow, 2006, p. 28; Rawson, 1985, pp. 100-114; Hidber, 2011, pp. 115-123). Uno de los caminos que un intelectual griego podía usar para llegar a hacerse de los favores de las familias romanas era convertirse en consejero o maestro (Yarrow, 2006, p. 46). El caso de Diodoro parece romper la regla. En su obra no hay indicio de que formara parte de algún círculo de intelectuales cercano a una de las familias aristocráticas romanas. La mención más temprana sobre Diodoro se ubica en Plinio (Plin., NH. praef. 25), por lo que no sabemos nada respecto a su fama en vida. Tampoco sabemos que se haya dedicado a la enseñanza o a la retórica en Roma para sostenerse, ni dedica su obra a algún amigo o patrón romano. La importancia de los griegos como maestros e intelectuales estuvo acompañada del aprecio generalizado como rétores, gramáticos, poetas e historiadores (Sacks, 1990, p. 185; Crawford, 1978, pp. 193-207). El mismo Diodoro critica la superficialidad y la búsqueda de negocio por parte de los griegos en un breve alegato (2.29.6). Más adelante afirma que entre los filósofos de su tiempo, "es posible ver que la mayor parte predican los principios más nobles, pero actúan de la manera más innoble, y que la respetabilidad y la inteligencia de sus exposiciones son desvirtuadas por la práctica" (9.9).
} 
La postura de Diodoro frente a Roma, y en particular a su política imperialista, no parece ser unidireccional, homogénea, ni clara, pues, aparecen contradicciones que difícilmente permiten obtener una visión concisa de cómo Diodoro percibió el dominio romano. En los primeros libros de la Biblioteca, Roma juega un papel insignificante. No es sino hasta el relato de la Primera Guerra Púnica (a partir del libro XXIII) que aparece como un protagonista más. Si algo es claro es que Roma no es el tema central de la Biblioteca y que la perspectiva universal de Diodoro no descansa en el desarrollo histórico de la ciudad del Tíber como el centro hacia el cual convergen las demás historias locales. Si bien algunas de las críticas y actitudes positivas frente a Roma pudieron haber sido tomadas de sus fuentes (Sacks, 1990, pp. 125-126), podemos observar algunos pasajes en donde el autor vierte su opinión sobre la hegemonía romana. Para Sacks (1990, pp. 127154), en las narraciones de la Primera Guerra Púnica, la Guerra Aquea y las Guerras Serviles en Sicilia, Diodoro pronuncia sentimientos sutiles de oposición frente a Roma, mostrándose claramente incómodo con los logros romanos. Su condición de siciliano probablemente explique lo anterior, si tomamos en cuenta su postura respecto a la tiranía y los acontecimientos en la isla. ${ }^{26}$

En la historiografía moderna ya se ha abordado de manera sistemática el problema de la postura de Diodoro sobre la hegemonía romana. ${ }^{27}$ Señalo algunos puntos encontrados en las propuestas y agrego el propio. Roma aparece inserta en un proceso mayor en el cual puede evidenciarse el papel de la Providencia, y los hechos beneficiosos y moderados llevados a cabo por los hombres (griegos y bárbaros) y vertidos en la historia con el fin de servir de modelo de comportamiento y aprendizaje de los hechos justos, así como de los viles.

Lens Tuero escribió un par de artículos en relación con la perspectiva de Diodoro frente a Roma. ${ }^{28}$ En ellos, el autor defiende la postura de que Diodoro creó dos modelos

\footnotetext{
${ }^{26}$ En 19.1.5 Diodoro señala a Roma como la responsable de haber expulsado de Sicilia a los tiranos, algo que parece agradecer. En otro punto, Diodoro enfatiza la gravedad de la tiranía considerándola, junto con la discordia civil y la guerra, como una de las tres mayores desventuras (9.11.1). En los últimos años, Sicilia había sido testigo de las Guerras Civiles y la isla no pasó desapercibida a los principales protagonistas de los momentos finales de la república. Según Diodoro, los sicilianos recibieron la ciudadanía romana de pleno derecho $(13.35 .3 ; 16.70 .6)$. Estos pasajes deben referirse al otorgamiento de ciudadanía a los sicilianos señalado por Cicerón (Att. 14.12), acto perpetrado por Antonio a partir de una ley promulgada por César, aunque en 36 les fueron revocados por orden de Augusto. El evento más tardío que se menciona en la Biblioteca es la expulsión de los griegos de Tauromenio y su reemplazo por colonos romanos (16.7.1), aunque el hecho no es datado por Diodoro. Esto ha llevado a una serie de especulaciones apoyadas en evidencia literaria posterior (App. B. Civ. 5.1.29; 5.13.31). Rubincam (1985: 521-522) abordó la política de castigo y reconstrucción que tuvo lugar en Sicilia por parte de Augusto tras la participación de las ciudades griegas en la guerra contra Sexto Pompeyo, la cual terminó con la batalla de Nauloco en 36. Según la autora, quien a su vez sigue a Burton (1972), los castigos a las ciudades involucradas fueron inmediatos, lo cual ubicaría el hecho narrado por Diodoro en el año 36. Para la política romana en Sicilia entre el 44 y el 20, además de Rubincam, cf. Stone (1983), Gabba y Vallet (1980).

${ }^{27}$ Prácticamente todo texto relativo a la obra de Diodoro aborda el problema. De manera reciente Muntz (2017), Sulimani (2011), aunque también Sacks (1990), Lens Tuero (1994a; 1994b), Yarrow (2006), Nieto Orriols (2015).

${ }^{28}$ Lens Tuero (1994a; 1994b).
} 
respecto al imperialismo a los que llama teoría simple y teoría compleja (Lens Tuero, 1994b, p. 395). El primero hace referencia a que los imperios se ganan mediante la preparación militar, el valor y la inteligencia y se mantienen mediante la práctica de las virtudes sociales como la benevolencia y la equidad humanitaria. En el segundo modelo, los imperios se ganan mediante el valor y la inteligencia militares, se amplían mediante la benevolencia y la equidad humanitaria hacia los nuevos súbditos y se fortalecen por medio del miedo y el terror. Lens Tuero aclara que el primero de ellos aparece de manera mucho más abundante que el segundo. Aquí, lo relevante es que Diodoro aplica el segundo modelo en un contexto romano, cuando narra lo acontecido con posterioridad al año 150 (32.2). ${ }^{29}$

Recientemente, Nieto Orriols (2015) retomó la teoría compleja de Lens Tuero. Ambos, junto con De Romilly (1979), apoyan una postura más optimista de Diodoro respecto a Roma, la que, dicen, justifica el uso de la fuerza y el terror como modalidad legítima de conquista (Nieto Orriols, 2015, p. 15). Este argumento está construido a partir de las siguientes palabras de Diodoro: “Las pruebas de estas proposiciones deben encontrarse en atenta consideración de la historia de dichos imperios, tanto de aquellos creados en tiempos antiguos, como al dominio romano que los sucedió" (32.2). Lens Tuero (1994a, p. 184) advirtió incluso que, cuando Roma había actuado con violencia, había sido por no tener alternativa y porque la Providencia quiso que así fuera. En los mismos Estudios sobre Diodoro, Camacho (1994, p. 97) propuso que aun cuando un evento pudiera parecer execrable a primera vista, bien podía constituir una "vindicación providencialista ante otro previo de connotaciones peores". La conquista romana no siempre fue un proceso pacificador solo por señalar que no destruía a los pueblos (32.6.1). Nieto utiliza el pasaje en 4.19 para decir que las conquistas eran un proceso civilizador y beneficioso para los pueblos sometidos. Sin embargo, en ese pasaje, donde habla de César, no hace referencia a Roma como un agente civilizador, de hecho, solo señala que Heracles mezcló a muchos nativos con los habitantes de la ciudad convirtiéndolos en bárbaros, quienes lograron mantenerla libre e inexpugnable hasta la llegada de César. Considero que el pasaje está ubicado ahí más en función de explicar su postura frente a César, ${ }^{30}$ que, frente a Roma,

\footnotetext{
${ }^{29}$ También lo aplica en otros contextos, por ejemplo, el endurecimiento de la política ateniense durante la Guerra del Peloponeso (12.76.3); o el comportamiento de Antípatro contra los griegos durante la Guerra Lamiaca (18.17.7).

${ }^{30}$ Cuando al inicio de su obra Diodoro establece como marcas cronológicas la Guerra de Troya, la muerte de Alejandro Magno y el inicio de la guerra contra los galos (1.4.6-7), parece estar dando un papel importante a los hechos protagonizados por Julio César. Junto con Gelón (baste ver sus palabras en 1.38.5-7) César y Alejandro parecen ser los personajes históricos a quienes Diodoro tiene en más alta estima. La primera mención a César está en el pasaje arriba citado sobre la metodología de su obra. En ella, Diodoro menciona a César como el "llamado dios a causa de sus hechos" (1.4.7). Las menciones sobre el personaje en los primeros cinco libros están en 3.82.2; 4.19.2; 5.21.2; 22.1; 25.4. En la primera solo hace referencia a los hechos de Britania que promete narrar en su momento (y que no lo hace). Sin embargo, tres de estas menciones posteriores llaman la atención. Diodoro cuenta la fundación de Alesia, ciudad que permaneció libre desde tiempo de Heracles hasta que Cayo César "que por la importancia de sus acciones ha recibido el calificativo de divino" la capturó (4.19.2). Destaca la descripción de César en 32.27.3 como fundador de ciudades, buen
} 
a la cual no siempre alaba. ${ }^{31}$ Además, la postura asumida respecto a Roma no puede equipararse a lo explicado con los otros pueblos, por la simple razón de que Roma no ha cedido su papel hegemónico, es decir no ha perdido el poder. Las críticas a Roma son abundantes y Diodoro parece no empatizar con lo sucedido particularmente en Sicilia. La modificación de su modelo simple hacia uno complejo puede responder al hecho de querer aplicarlo a una situación contemporánea (Sacks, 1990, pp. 45-46). Por eso, la realidad del siglo primero debió estar presente a la hora de la escritura de la Biblioteca.

De manera constante Diodoro hace alusión al comportamiento que llevó a los imperios a caer, dejando de actuar de manera moderada y empezando a hacerlo duramente:

Los atenienses, en efecto, con el notable incremento de su potencia, ya no solían tratar a sus aliados con moderación como hacían antes, sino que ejercían su hegemonía con violencia y arrogancia. Por esta razón la mayor parte de los aliados, no pudiendo soportar aquella carga, empezaron a mantener conversaciones unos con otros respecto a una posible defección, y algunos, sin prestar atención al congreso federal, empezaron a actuar por su cuenta (11.70.3-4).

Más adelante agrega:

Entre los atenienses, por ejemplo, treinta hombres que se convirtieron en tiranos, movidos por su codicia, precipitaron a su patria en los más graves infortunios y ellos mismos perdieron rápidamente el poder dejando un recuerdo eterno de su ignominia; y los lacedemonios, que habían obtenido el dominio indiscutible de Grecia, lo perdieron cuando comenzaron a cometer injusticias contra sus aliados. La autoridad de los que mandan se mantiene gracias a su benevolencia y a su justicia, pero la minan las injusticias y el odio de los súbditos. (14.2.1-2).

El mismo criterio es empleado en otros puntos, fuera y dentro del ámbito griego y en tiempos míticos e históricos. Como ejemplos, se pueden mencionar: el comportamiento violento de Amasis, que llevó a la caída de Egipto frente a Actísanes, rey de los etíopes (1.60.1-3); Cronos, por su comportamiento sobre las tierras de Amón, que provocó el levantamiento de Dioniso, quien reunió soldados de Nisa, libios y amazonas y sometió gran parte del mundo habitado hiriendo a Cronos (3.71.3-4); los atenienses, una vez que obtuvieron mucho poder, dejaron de tratar a sus aliados justamente y los mandaban dura y arrogantemente provocando que muchos de ellos discutieran la posibilidad de rebelarse y algunos incluso actuaban ya como Estados independientes (11.70.3-4);

\footnotetext{
legislador, capaz de mostrar un alto grado de clemencia, y fue justamente llamado un dios, superó a todos los romanos anteriores en la magnitud de sus hechos; aunado a esto, enmendó la conducta severa de sus antepasados hacia la ciudad, prefirió el perdón antes que el castigo. Además, César aparece ligado a la figura de Heracles, uno de los personajes centrales de la primera parte de la obra y el ejemplo paradigmático de benefactor. Incluso se le ve como moderado y clemente, las más benéficas formas de comportamiento para Diodoro.

${ }^{31}$ Cf. 30.21.1; 32.4.26, 33.26.2. Sacks (1990) y Sheridan (2010) coinciden en que Diodoro no fijó una postura favorable respecto al dominio romano.
} 
Hierón de Siracusa, a diferencia de su hermano Gelón, quien había expulsado a los cartagineses de la isla, fue violento y codicioso al igual que Trasíbulo, quien lo sucedió y superó en perversidad, obligando a sus súbditos a sublevarse en masa para liberarse así de la tiranía (11.67-68); Nicolao, en su discurso, aconseja la moderación como vehículo del bienestar general (13.20-27); los habitantes de Larisa conspiraron contra el tirano de Feras, Alejandro, por el mal trato recibido lo que provocó su caída (15.61.2-3). Estos y otros ejemplos sirven para observar el patrón que Diodoro encuentra en la caída de las ciudades, imperios o regímenes políticos como resultado del mal trato a los súbditos. Por cierto, no puede haber una única fuente de donde Diodoro haya copiado lo anterior, pues, ninguna de las obras tradicionalmente consideradas sus fuentes contienen una narración completa en donde se integren todos los ejemplos señalados. De lo anterior, se desprende que esta postura puede ser idea original de Diodoro centrada en la finalidad moral de su obra y aplicada a distintos momentos y espacios, vinculada así con su perspectiva de la historia universal. Por lo tanto, la conducta moderada es la que direcciona el devenir de individuos y naciones. El siguiente pasaje resume lo comentado:

Aquellos cuyo objeto es ganar dominio sobre otros usan coraje e inteligencia para obtenerlo, moderación y consideración hacia otros para extenderlo y terror paralizante para asegurarlo contra el ataque. Las pruebas de estas proposiciones deben encontrarse en atenta consideración de la historia de dichos imperios, tanto de aquellos creados en tiempos antiguos, como al dominio romano que los sucedió (32.2).

Roma impuso su dominio por medio del terror al destruir Corinto, Macedonia y Numancia (32.4.4-5). Sirva como ejemplo aquí para observar la aplicación de su postura sobre la decadencia de los imperios. En ese ámbito, Roma está incluida, como lo está en la dinámica de la sucesión de imperios y la caída de los mismos, solo comprensible en un contexto amplio provisto por la historia universal.

\section{Beneficio, estoicismo y modelo organizativo}

En los capítulos 6 y 7 del primer libro, Diodoro reconoce dos explicaciones respecto al origen de los hombres. La primera de ellas defiende que el hombre y el universo siempre han existido; la segunda afirma que el universo es generado y perecedero y que los hombres alcanzaron su origen primero en un tiempo determinado (1.6.3). En seguida expone los argumentos de esta segunda explicación (1.7), que incluye el origen de los animales y su distribución. Lo que interesa aquí es el proceso por el que el hombre ha pasado desde su origen y explica que:

Los primeros hombres, pues, no descubierta aún ninguna cosa útil para la vida, vivían penosamente, desnudos de ropa, ajenos a la vivienda y al fuego y desconocían totalmente el alimento cultivado. Desconociendo también la recolección del alimento silvestre, no hacían ninguna provisión de frutos en caso de penuria; y, por tanto, muchos de ellos 
perecían durante los inviernos a causa del frío y de la escasez del alimento. Pero, después de eso, instruidos poco a poco por la experiencia, se refugiaron en las cuevas en invierno y almacenaron los frutos capaces de ser guardados. Conocido el fuego y las demás cosas útiles, descubrieron también paulatinamente las técnicas y los demás instrumentos de favorecer la vida común. En general, la utilidad misma fue maestra de todas las cosas para los hombres, y dirigió adecuadamente en el aprendizaje de cada cosa a un ser bien dispuesto y poseedor de manos hábiles, de razón y de agudeza de espíritu para todo. (1.8.59).

De lo anterior puede decirse que los hombres fueron forzados a aprender a partir de la

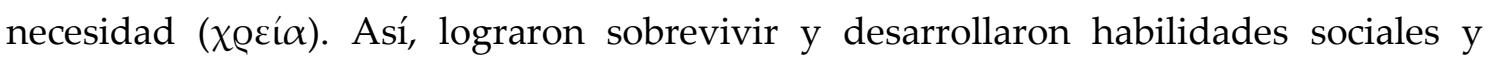
tecnológicas que favorecieron a la vida común. Además, la necesidad aparece como maestra ( $\delta\llcorner\delta \alpha ́ \sigma \kappa \alpha \lambda o \varsigma)$ de la humanidad. Finalmente, fue la misma necesidad la que “dirigió adecuadamente en el aprendizaje de cada cosa a un ser bien dispuesto y poseedor de manos hábiles, de razón y de agudeza de espíritu para todo" (1.8.9). Es decir, las circunstancias provocadas por la necesidad/experiencia y las acciones de un individuo en estas circunstancias son las que actúan como fuerzas civilizadoras o agentes del progreso de la cultura, pensamiento claramente inserto en el ámbito del estoicismo. ${ }^{32}$ Momigliano (1984, p. 271) afirmó que los dioses o héroes culturales, que revelan secretos tecnológicos para ayudar a la humanidad, pueden encontrarse en todos lados. $^{33}$ Estos individuos son tratados como benefactores, que, con sus acciones ( $\varepsilon \dot{v} \varepsilon \varrho \gamma \varepsilon \sigma i ́ \alpha)$, ganaron inmortalidad al provocar el desarrollo del género humano como colectividad (Sacks, 1990, p. 61). ${ }^{34}$ Es decir, se evidencia la dimensión universal de la naturaleza humana observable en el ámbito griego, así como en el bárbaro; tanto en los mitos como en el tiempo histórico. El beneficio además podía desembocar en el reconocimiento del benefactor como deidad. ${ }^{35}$

Como puede observarse, la aplicación de estas categorías con relación al progreso de la cultura y los benefactores parece ser propia de Diodoro, aunque, como se ha dicho, ajustada a su propio tiempo. Esta perspectiva no escapa a su idea de universalidad debido a que, por un lado, el beneficio obtenido es para toda la humanidad, así como su

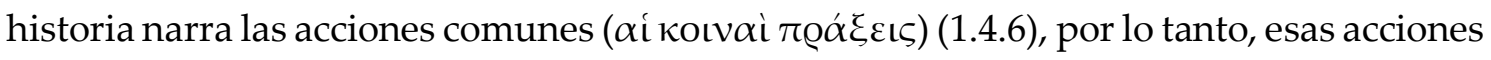

\footnotetext{
32 Spoerri (1959) fue quien primero evidenció los antecedentes estoicos en Diodoro.

33 Junto a Diodoro, contemporáneos como Lucrecio y Vitruvio se plantearon problemas similares (Cole, 1967, pp. 48-49) lo cual apunta, en concordancia con lo expuesto por Sacks (1990, pp. 55-83) a que Diodoro sintetiza el pensamiento de su propio tiempo y, a la vez, recupera lo planteado hasta entonces por las diversas corrientes filosóficas. Además, al inicio del capítulo en cuestión, el siciliano afirma que expone lo que "hemos recogido" (1.8.1).

34 Para un estudio sobre 1.7-8: Cole (1967, pp. 174-192). El autor defiende la autoría de Diodoro de estos pasajes, proponiendo un orden distinto al momento de la planeación de la obra. Ejemplos de estos benefactores pueden encontrarse a lo largo de todo el texto, y personificados tanto por griegos como por bárbaros; así como por héroes míticos o personajes históricos.

${ }^{35}$ Sacks contabilizó setenta ocasiones (1990, p. 71) en los primeros seis libros en los que el beneficio de un individuo a la humanidad provocó que fuera considerado un dios. Cf. Sacks, 1990, p. 71, n. 79. Algunos ejemplos: $1.13 .1 ; 2.4 ; 2.38 .5 ; 4.1 .4 ; 5.64 .2$.
} 
y beneficios comunes necesariamente deben ser tratados de manera conjunta; por otro lado, no son privativos del mundo griego, sino que podemos encontrarlos en el relato tanto mitológico como histórico de bárbaros y griegos, de ahí la distribución de los primeros seis libros (I-III, para bárbaros, IV-VI, para griegos). Como apuntó Sacks (1990, p. 78), el beneficio otorgado produce gratitud y la evergesía está vinculada con conceptos

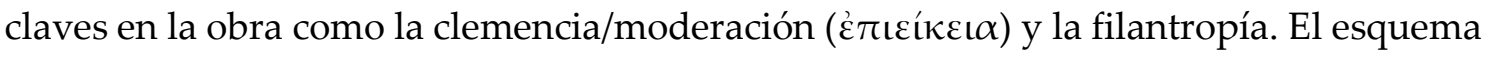
de la necesidad/beneficio no es privativo de los tiempos míticos, sino que también se halla en la parte histórica del texto. ${ }^{36}$ En esta, Diodoro enfatiza en el tema de los benefactores como héroes culturales y su veneración como dioses. Entre casi una docena de individuos deificados (Sacks, 1990, p. 73), sobresalen Gelón (11.38.5-6), Alejandro (17.102.4) y el propio César $(1.4 .7 ; 4.19 .2)$.

De lo señalado hasta aquí se desprende que la historicidad de la que los mitos carecen no parece importar a Diodoro para aplicar en ellos el mismo juicio sobre la necesidad y el beneficio que algunos hombres/dioses realizan por el bien común. Por lo tanto, desde Osiris, (1.17.1-2), Dioniso (2.38.5), Heracles (1.24.7), Sesostris (3.61.4), Zeus (3.75.1), Teseo (4.62.4), Deméter (5.68.3), las Musas (5.74.1), hasta Gelón y César, son las acciones que los individuos realizan por el bien común y registradas por la historia, que, a su vez, funge como benefactora, las que catalizan el progreso de la humanidad como colectividad. La historia funciona como maestra para toda la sociedad (jóvenes, ancianos, ciudadanos y gobernantes: 1.1.5) y transmite la experiencia, dado que el aprendizaje por la experimentación implica "muchos trabajos y peligros" (1.1.2). Por lo tanto, la experiencia puede ser adquirida a través de la historia. Los historiadores, "con sus trabajos particulares, se afanaron en favorecer la vida común ( ofreciendo sin peligro la enseñanza de lo conveniente" (1.1.1). Gracias a la historia, "unos fueron incitados a convertirse en fundadores de ciudades; otros, a introducir leyes que promovieran la seguridad para la vida común ( $\tau \tilde{\omega}$ kotv $\tilde{\omega} \beta i ́ \omega)$; y muchos se afanaron en descubrir ciencias y artes para beneficio del género humano (

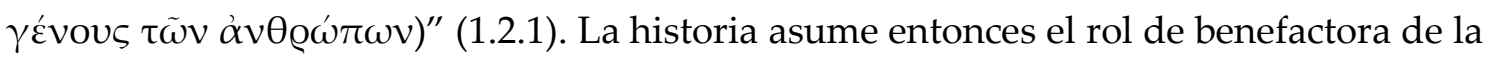

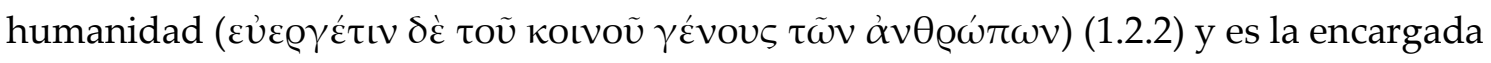
de inmortalizar las virtudes de los hombres (1.2.4). ${ }^{37}$ Tanto los valores mostrados, como los beneficios, tienen carácter universal. He de señalar que los conceptos de moderación, filantropía, evergesía y la veneración por los servicios excepcionales eran centrales en el pensamiento político y social del período helenístico y de la Roma tardorrepublicana (Sacks, 1990, pp. 69-78; Aalders, 1975; Spoerri, 1959, pp. 64-73).

\footnotetext{
${ }^{36}$ Ejemplos en $11.66 .4 ; 13.35 .2 ; 16.20 .6 ; 17.102 .4 ; 17.115 .6 ; 20.100 .3$, entre otros.

${ }^{37}$ Además del prefacio general, en el libro X retoma las mismas ideas y agrega: “Es hermoso además que las generaciones futuras tengan como principio fundamental que cada hombre, cualquiera que sea el modo de vida que haya elegido vivir, merecerá después de su muerte un recuerdo en consonancia con su conducta, y ello a fin de que estas generaciones no se afanen en la construcción de monumentos conmemorativos de piedra, que están limitados a un único lugar y se ven expuestos a una rápida mina, sino en alcanzar la inteligencia y las demás virtudes que mediante la fama llegan a todos los lugares" (10.12).
} 
En la Biblioteca aparece una relación universal de los hechos de griegos y bárbaros. Para él, los historiadores universales "se esforzaron en reunir a todos los hombres, partícipes del mismo linaje unos y otros, pero separados por espacio y tiempo, en una única e idéntica composición, como si fueran ministros de la divina Providencia," es decir, crearon una relación universal de los hechos en el momento en que los vincularon nutridos de una intervención providencial en la historia que dotó y repartió "a cada uno lo asignado por el destino" (1.1.3).

En los pasajes con los que comencé la explicación (1.6-8) se puede observar que Diodoro no ve en el pasado una edad dorada que emular, sino que la historia parece guiarse por un desarrollo lineal y progresivo. Sheridan (2010, p. 49) propone que el avance inicia desde el pasado mítico con dirección a su propio presente y es tarea del historiador capturar ese movimiento. En parte coincido con el autor, pero creo que en Diodoro el tiempo humano no está configurado como resultado del avance lineal del tiempo mítico hacia el humano. En ocasiones, el historiador alude a un escepticismo generalizado en torno a los mitos $(1.23 .8 ; 4.1 .8)$. Más allá de la cronología como marca útil para la universalidad, el tratamiento tanto de mitos como de hechos acaecidos en el tiempo histórico/humano, le permiten mostrar valores universales y compartidos, pues los mismos se observan en ambas partes de la narración. Del mismo modo, el avance progresivo de la humanidad no solo depende del tiempo transcurrido, sino de la necesidad/experiencia y de las acciones de los benefactores (ya sean míticos o históricos) para poder llevarse a cabo. Por lo tanto, la perspectiva cíclica del devenir, la intervención providencial en la historia, la universalidad de las acciones humanas en el entorno del mundo helenístico y el fin de la república romana, vincula claramente a Diodoro con el estoicismo. Muchas de estas improntas filosóficas pueden evidenciarse en el proemio general de la obra (1.2.2). Por el momento, cabe insertarlas en su perspectiva universal, es decir, son congruentes con su objetivo.

En vista de lo anterior, Diodoro buscó incluir en su Biblioteca los hechos acontecidos hasta su propia época, ${ }^{38}$ tanto de griegos como de bárbaros -quienes caben en su definición de universalidad-, explicar los mitos y ponerlo todo en una sola obra tratados como los de una sola ciudad (1.3.2-6). La perspectiva universalista de Diodoro se cumple al incluir todo lo anterior en su obra y tratarlo de manera paralela, de ahí su narración lógico/cronológica que aborda los hechos acontecidos en todo el mundo conocido en un solo tiempo. La dificultad que esto implicó, y que él mismo señala, provocó que, en su obra, se buscara igualar en una sola cronología todos los hechos. Los mitos no están fechados por carecer de cronología para ellos, por lo tanto, establece su punto de partida en la guerra de Troya. A partir de esta, fija la fecha del regreso de los Heráclidas al Peloponeso (80 años), la primera olimpiada (328 años después), la Guerra Céltica (730 años después), es decir abarca 1138 años, además de los hechos comprendidos antes de

${ }^{38}$ Según Sacks (1990, pp. 169-184) y Green (2006, p. 30), la obra de Diodoro debió terminar alrededor del año 60. 
los troyanos, en cuarenta libros (1.5.1). El tiempo en Diodoro es en definitiva un factor dentro de su visión universalista, pues, se remonta a los hechos más remotos y busca terminar su relación de acontecimientos en su propio presente.

En lo anterior se observa su manera de organizar cronológicamente el material. Antes de la primera olimpiada, trata los asuntos por categorías buscando empalmar los hechos acontecidos. Posteriormente, emplea diversas cronologías locales y arregla el material por años con el uso de tres marcas: los arcontes atenienses, los cónsules romanos y los ganadores de la justa olímpica. Sin duda, esta disposición generó problemas y ha sido objeto de críticas por la historiografía moderna debido a la falta de precisión al tratar de narrar acontecimientos de distintos lugares en el mismo tiempo (Rhodes, 1994, p. 167). ${ }^{39}$ Además, Diodoro constantemente prefiere narrar un acontecimiento de principio a fin, aunque suceda a lo largo de más de un año, provocando así un desfase en la narración. Sin embargo, él mismo justifica su actuar en el libro XX donde no solo defiende su decisión de narrar "procesos" completos, sino que también critica a quienes, por incluir discursos, cortan la narración. ${ }^{40}$ Prefiere ante todo no interrumpir el interés de aquellos que esperan ansiosamente un conocimiento completo de los eventos (20.1.1). ${ }^{41}$ Recordemos que el autor, desde su proemio general enfatiza el papel de la historia como benefactora y útil para aquellos que desean aprender de los fracasos y éxitos ajenos. Esta utilidad del testimonio histórico solo puede cumplirse si se construye una lectura cómoda y fácil de seguir, pues, "es más útil el todo que la parte y lo continuo que lo fragmentario" (1.3.8). En consecuencia, cuando en el libro XX asegura que:

Uno podría censurar a la historia, cuando observe que en la vida muchas distintas acciones son consumadas al mismo tiempo, pero que es necesario para aquellos que las registran interrumpir la narrativa y repartir diferentes tiempos a eventos simultáneos contrario a la naturaleza; con el resultado de que la experiencia de los eventos contiene la verdad, pero la narración, desprovista de dicho poder, al presentar copias de los eventos, se queda corta en arreglarlos como realmente fueron (20.43.7).

Diodoro no hace más que seguir la misma idea tratada en su proemio sobre la necesidad de hacer la lectura estilísticamente agradable pues solo así puede cumplir su función moral y didáctica.

El énfasis que Diodoro pone sobre la utilidad de la historia a lo largo de todo el prefacio $(1.1 .1 ; 1.4-5)$ guía su explicación de la necesidad de una visión universal del devenir histórico, pues es la historia quien ha incitado a los hombres a "convertirse en fundadores de ciudades; otros a introducir leyes que promovieran la seguridad para la vida común; y muchos se afanaron en descubrir ciencias y artes para beneficio del género

\footnotetext{
${ }^{39}$ No es objetivo de este estudio profundizar en las críticas a la cronología dictada por Diodoro. Remito a algunos textos referentes a este problema: Parreu Alasa (2001, pp. 46-49), Rubincam (1998).

${ }^{40}$ Para un análisis profundo sobre el proemio al libro XX, ver: Achilli (2012).

${ }^{41}$ Otro ejemplo puede encontrarse en 17.1.1-2.
} 
humano" (1.2.1). La historia no solo rememora lo bueno, sino también acusa a los viles (1.2.8). La utilidad que el quehacer histórico implica puede observarse no solo en su introducción general, sino también a lo largo de su obra, en particular en 10.12 donde retoma algunas ideas planteadas al inicio del texto. ${ }^{42}$

Respecto al espacio, la obra de Diodoro abarca todo el mundo conocido. Es necesario aclarar que la naturaleza fragmentaria de la obra imposibilita conocer todo lo contenido en ella. Sin embargo, podemos señalar de manera general la forma en la que está compuesta. Los primeros seis libros narran la historia y mitos de griegos y bárbaros por regiones geográficas: Egipto, Mesopotamia, India, Escitia, Arabia, África (I-III), Grecia, las islas y el resto de Europa (IV-VI). A partir del libro VII, se narran los hechos

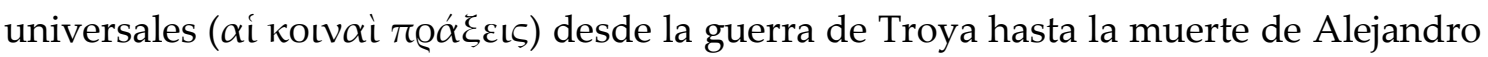
de Macedonia (Libro XVII). Finalmente, los libros XVIII al XL contienen la narración de los hechos desde la muerte de Alejandro hasta la Guerra de las Galias comandada por Julio César. ${ }^{43}$ Como puede observarse, la Biblioteca contiene los hechos de toda la ecúmene, y agrega relatos en donde se narran lugares fantásticos como el viaje de Yámbulo a las islas del Sol (2.55-60), las cuales, por cierto, ubica fuera del mundo conocido (2.56.2), o el relato de Evémero sobre la isla de Panquea (6.1). Estos relatos de maravillas también cumplen una función didáctica dentro del discurso universal. ${ }^{44}$

Lo anterior deja clara la condición espacio/temporal de la Biblioteca Histórica. No obstante, no es esta condición la que define la universalidad de la historia en Diodoro. Para él, es necesario establecer el vínculo entre los hechos para que aparezcan como si se tratara de un solo proceso histórico. En este vínculo, el beneficio que la escritura de la historia provoca a sus lectores es muy importante, así como el papel del azar/fortuna/Providencia y su teoría sobre el declive de los imperios (Sacks, 1990, p. 23). Estos elementos provocan que las historias de distintos lugares y tiempos puedan ser tratadas como una sola.

\section{Consideraciones finales}

Diodoro empleó los dos criterios indispensables de la universalidad en la historia, trató lo acontecido desde los tiempos más remotos hasta su presente y cubrió la totalidad del mundo habitado tanto geográfica como etnográficamente. Además, lidió con los eventos a partir de un vínculo establecido entre ellos con el fin último de exponer un relato útil para sus lectores. El historiador siciliano se coloca a sí mismo en una tradición de autores de historia universal que se ocuparon de describir las acciones universales del mundo habitado como las de una sola ciudad.

\footnotetext{
42 Otros ejemplos en 9.33.1; 11.38 .6 ; 30.15.1.

${ }^{43}$ Debido a que el último libro está perdido solo podemos especular respecto al punto final de la obra. En su prefacio general (1.5.1), Diodoro señala que su obra abarcará hasta la Guerra Céltica, es decir el año 60/59. Para un análisis sobre la posible fecha final de su obra, ver: Burton (1972, pp. 40-41); Rubincam (1998, pp. 229-233).

${ }^{44}$ Estos relatos, según Gómez Espelosín (2006), se convirtieron en el escenario perfecto en donde ubicar sociedades ficticias ideales y perfectas contrarias a la realidad griega.
} 
El estudio de la obra de Diodoro debe estar siempre encaminado a mantener la unidad del texto. Se observó que el historiador natural de Agirio fue responsable de la creación de una perspectiva universal de la historia en la cual solo las acciones universales del mundo habitado posibilitan un estudio unificado y un vínculo entre lo acontecido en diferentes lugares o en distintos tiempos. La pretensión de escribir una obra de este tipo requirió de la creación de esquemas de explicación histórica. Diodoro los encontró en el desarrollo de la humanidad a partir de la necesidad y los benefactores. Esto no pudo desarrollarse teniendo en mente solo el marco temporal o espacial, sino que requirió de un vínculo que le permitiera tratar los hechos de todos los tiempos. La universalidad en Diodoro necesitó también del tratamiento de los hechos de los bárbaros. La inclusión de estos en las proporciones observables es significativo y sintomático del proceso de autodefinición griega propio de su tiempo.

Con su propia idea de la sucesión de imperios, tuvo un sitio en donde acomodar a los romanos. En ellos, como en los griegos y en los bárbaros, se aplicó la misma postura sobre los benefactores como individuos capaces de catalizar el desarrollo de la colectividad. Es decir, el benefactor promueve el bien común dentro de una historia común, por lo tanto, esas acciones y beneficios comunes necesariamente deben ser tratados de manera conjunta. Para lograrlo, insertó a Roma en su modelo explicativo nutrido del esquema de la sucesión de los imperios arraigado en la historiografía del final de la república. Roma quedó sujeta a las valoraciones morales que nutren todo el texto como son las formas adecuadas de mantener el poder, el beneficio otorgado a la humanidad y la naturaleza común de las acciones humanas. Además, al ser común el beneficio, tanto benefactores como beneficios pueden encontrarse en el relato tanto mitológico como histórico de bárbaros y griegos. Para probar esto, tuvo que conceder un importante papel a las civilizaciones antiguas. Al final, la historia de Roma no solo cobró sentido en una perspectiva universal, sino que quedó inserta en ella. El tratamiento de los hechos romanos quedó subordinado a un objetivo mayor, la función moralizante de la historia.

El historiador siciliano vio en la historia universal la más concreta y completa forma de narración que le permitió enseñar a partir de los fracasos y los éxitos ajenos. Al describir las acciones universales del mundo habitado, presentó en su obra un estudio unificado en donde la historia incluso puede afectar acciones futuras (1.5; 2.1-5) y alabó el quehacer de los historiadores universales (1.3). Además, en el discurso universal afirmó que puede observase a la Divina Providencia "reuniendo el orden de los astros visibles y la naturaleza de los hombres en una relación universal, los hace girar continuamente toda la eternidad, repartiendo a cada uno lo asignado por el destino" (1.1.3). En tono apologético, defendió la validez de su trabajo (1.3-5) y la dificultad de su empresa (1.4.1). Si tomamos en cuenta todo lo anterior, la justificación y elogio de la historia (entendida como universal) que hace Diodoro en su proemio adquiere mayor sentido. 


\section{Ediciones, traducciones y comentarios de Diodoro}

Ambaglio, D., Landucci, F. y Bravi, L. (2008). Diodoro Siculo. Biblioteca Storica. Commento storico: Introduzione generale. Milán: Vita e Pensiero.

Burton, A. (1972). Diodorus Siculus, Book I: A Commentary. Leiden: Brill.

Green, P. (2006). Diodorus Siculus Books 11- 12.37.1: Greek History, 480-431 BC- the Alternative Version. Austin: University of Texas Press.

Oldfather, C. H. et al. (1933-1967). Diodorus Siculus: Library of History. 12 vols. Cambridge, MA: Harvard University Press.

Stylianou, P. J. (1998). A Historical Commentary on Diodorus Siculus, Book 15. Oxford: Clarendon Press.

Parreu Alasa, F. y Torres Esbarranch, J. J. (2001-2014). Diodoro de Sicilia: Biblioteca Histórica, 6 vols. Madrid: Gredos.

\section{Referencias bibliográficas:}

Aalders, G. J. P. (1975). Political Thought in Hellenistic Time. Ámsterdam: A.M. Hakkert.

Achilli, I. (2012). Proemio del Libro 20 della Bibliotheca Storica di Diodoro Siculo. Lanciano: Carabba.

Alonso-Núñez, J. M. (1987). An Augustan World History: The Historiae Philippicae of Pompeius Trogus. GER 34, 56-72.

Alonso-Núñez, J. M. (1990). The Emergence of Universal Historiography from the 4th to 2nd Centuries BC. En H. Verdin, G. Schepens y E. De Keyser (Eds.), Purposes of History: Studies in Greek Historiography from the 4th to 2nd Centuries BC (pp. 173-192). Lovaina: Peeters.

Alonso-Núñez, J. M. (1992). La Historia universal de Pompeyo Trogo: coordenadas espaciales y temporales. Madrid: Ediciones Clásicas.

Alonso-Núñez, J. M. (2002). The Idea of Universal History in Greece: From Herodotus to the Age of Augustus. Amsterdam: J.C. Gieben.

Bigwood, J. M. (1980). Diodorus and Ctesias. Phoenix 34, 195-207.

Bosworth, A. B. (2003). Plus ça change... Ancient Historians and Their Sources. Cl. Ant. 22, 167-197.

Bruce, I. A. F. (1970). Theopompus and classical Greek historiography. HET 9, 86-109.

Brunt, P. A. (1980). On historical fragments and Epitomes. CQ, 30 (2), 477-494.

Burstein, S. (1989). Agatharchides of Cnidus: On the Erythraean Sea. Londres: Hakluyt Society.

Camacho Rojo, J. M. (1994). Actitudes del hombre frente a la Tyche en la Biblioteca Histórica de Diodoro de Sicilia. En J. Lens Tuero (Ed.), Estudios sobre Diodoro de Sicilia (pp. 97-116). Granada: Editorial de la Universidad de Granada.

Clarke, K. (1999). Universal Perspectives in Historiography. En C. S. Kraus (Ed.), The Limits of Historiography: Genre and Narrative in Ancient Historical Texts (pp. 249-279). Leiden: Brill. 
Clarke, K. (2008). Making Time for the Past: Local History and the Polis. Oxford: Oxford University Press.

Cole, Th. (1967). Democritus and the sources of Greek Anthropology. Chapel Hill: American Philological Association.

Cornell, T., Fear, A. y Liddel, P. (2010). Metabole Politeion as Universal Historiography. En P. Liddel y A. Fear (Eds.), Historiae Mundi: Studies in Universal Historiography (pp. 15-29). Londres: Duckworth.

Crawford, M. (1978). Greek Intellectuals and the Roman Aristocracy in the First Century BC. En P. D. A. Garnsey y Ch. R. Whittaker (Eds.), Imperialism in the Ancient World (pp. 193-207). Cambridge: Cambridge University Press.

De Romilly, J. (1977). The Rise and Fall of States according to Greek Authors. Ann Arbor: The University of Michigan Press.

Engels, J. (2010). Strabo and the Development of Ancient Greek Universal Historiography. En P. Liddel y A. Fear (Eds.), Historiae Mundi: Studies in Universal Historiography (pp. 71-86). Londres: Duckworth.

Farrington, B. (1947). Diodorus Siculus: Universal Historian. En B. Farrington, Head and Hand in Ancient Greece (pp. 55-87). Londres: Watts \& Co.

Flusser, D. (1972). The Four Empires in the Fourth Sibyl and in the Book of Daniel. Isr. Orient. Stud. 2, 148-175.

Gabba, E. (1984). The Historians and Augustus. En F. Millar y E. Segal (Eds.), Caesar Augustus: Seven Aspects (pp. 61-88). Oxford: Clarendon Press.

Gabba, E. y Vallet, G. (Eds.) (1980). La Sicilia antica 1 (1). Nápoles: Società Editrice Storia di Napoli e della Sicilia.

Gruen, E. (2011). Rethinking the other in Antiquity. Nueva Jersey: Princeton University Press.

Gómez Espelosín, F. J. (2006). Viajes de verdad viajes de mentira. Literatura de viajes del período helenístico. Revista de Filología Románica, Anejo IV, 59-75.

Gómez Espelosín, F. J. (2010). La imaginación geográfica en la expedición de Alejandro. En F. Marco Simon, F. Pina Polo y J. Remesal Rodríguez (Eds.), Viajeros, peregrinos y aventureros en el mundo antiguo (pp. 49-64). Barcelona: Universidad de Barcelona.

Hartog, F. (2010). Polybius and the First Universal History. En P. Liddel y A. Fear (Eds.), Historiae Mundi: Studies in Universal Historiography (pp. 30-40). Londres: Duckworth.

Hidber, T. (2011). Impacts of Writing in Rome: Greek Authors and Their Roman Environment in the First Century BCE. En T. A. Schmitz y N. Wiater (Eds.), The Struggle for Identity: Greeks and Their Past in the First Century BCE (pp. 115-123). Stuttgart: Franz Steiner Verlag.

Hornblower, J. (1981). Hieronymus of Cardia. Oxford: Oxford University Press.

Kramer, E. A. (2005). Book One of Velleius' 'History': Scope, Levels of Treatment, and Non-Roman Elements. Historia 54, 144-161.

Lenfant, D. (2007). Greek Historians of Persia. En J. Marincola (Eds.). A Companion to Greek and Roman Historiography (pp. 200-209). Oxford: Blackwell. 
Lens Tuero, J. (1994a). Sobre la problemática de la hegemonía en la Biblioteca Histórica de Diodoro de Sicilia. En Estudios sobre Diodoro de Sicilia (pp. 13-18). Granada: Universidad de Granada.

Lens Tuero, J. (1994b). La concepción del Imperialismo romano en la Biblioteca Histórica de Diodoro de Sicilia. En Estudios sobre Diodoro de Sicilia (pp. 169-186). Granada: Universidad de Granada.

Liddel, P. y Fear, A. (Eds.) (2010). Historiae Mundi: Studies in Universal History. Londres: Bloomsbury.

Llewellyn-Jones, L. y Robson, J. (2009). Ctesias' History of Persia: Tales of the Orient. Londres: Routledge.

Marincola, J. (1997). Authority and tradition in ancient historiography. Cambridge, Cambridge University Press.

Marincola, J. (2007). Universal History from Ephorus to Diodorus. En J. Marincola (Ed.), A Companion to Greek and Roman Historiography (pp. 171-179). Oxford, Blackwell.

Martínez Lacy, R. (2004). Historiadores e historiografía de la antigüedad clásica: Dos aproximaciones. México: Fondo de Cultura Económica.

Martínez Lacy, R. (2005). Estrategias narrativas de Justino/Trogo. Históricas 72, 2-7.

Mendels, D. (1981). The Five Empires: A Note on a Propagandistic Topos. AJPh 102, 330337.

Momigliano, A. (1984 [1982]). Los orígenes de la historia universal. En La historiografía griega. Barcelona: Crítica.

Momigliano, A. (1993 [1972]). La tradición y el historiador clásico. En su Ensayos de historiografía antigua y moderna. México: Fondo de Cultura Económica.

Moreno Leoni, A. (2017). Entre Roma y el mundo griego. Memoria, autorrepresentación y didáctica del poder en las Historias de Polibio. Córdoba: Editorial Brujas.

Muntz, C. E. (2017). Diodorus Siculus and the World of the Late Roman Republic. Oxford: Oxford University Press.

Nieto Orriols, D. (2015). Diodoro sículo y el imperialismo en la Biblioteca Histórica: consideraciones y problemas sobre las funciones moralizante y persuasivo-política de la conquista romana. Intus-Legere Historia 9 (1), 5-23.

Palm, J. (1955). Über Sprache und Stil des Diodoros von Sizilien. Lund: Gleerup.

Parmentier, É. y Barone, F. P. (2011). Nicolas de Damas. Histoires; Recueil de Coutumes; Vie d'Auguste, Autobiographie. París: Les Belles Lettres.

Rawson, E. (1985). Intellectual Life in the Late Roman Republic. Londres: Duckworth.

Rhodes, P. J. (1994). In Defense of the Greek Historians. GER 41 (2), 156-171.

Rubincam, C. (1985). The Chronology of the Punishment and Reconstruction of Sicily by Octavian/Augustus. AJA 89, 521-522.

Rubincam, C. (1987). The Organization and Composition of Diodorus' Bibliotheke. Echos du Monde Classique 31, 313-328. 
Rubincam, C. (1989). Cross-references in the Bibliotheke Historike of Diodoros. Phoenix 43, 39-61.

Rubincam, C. (1998a). Did Diodorus Siculus Take over Cross- References in His Sources? AJPh 119, 67-87.

Rubincam, C. (1998b). How Many Books Did Diodorus Siculus Originally Intend to Write? CQ N.S. 48, 229-233.

Sacks, K. (1981). The lesser Prooemia of Diodorus Siculus. Hermes 110, 431-441.

Sacks, K. (1990). Diodorus Siculus and the First Century. Nueva Jersey: Princeton University Press.

Schepens, G. (1977). Historiographical Problems in Ephorus. En Historiographia antiqua. Commentationes Lovanienses in honorem W. Peremans septuagenarii editae (pp. 95-118). Lovaina: University Press.

Sheridan, B. (2010). Diodorus' Reading of Polybius' Universalism. En P. Liddel y A. FEAR (Eds.), Historiae Mundi: Studies in Universal Historiography (pp. 41-55). Londres: Duckworth.

Spoerri, W. (1959). Späthellenistische Berichte über Welt, Kultur und Götter. Basilea: F. Reinhardt.

Stone III, S. C. (1983). Sextus Pompey, Octavian and Sicily. AJA 87, 11-22.

Sulimani, I. (2011). Diodorus' Mythistory and the Pagan Mission: Historiography and CultureBringers in the First Pentad of the Bibliotheke. Leiden: Brill.

Swain, J. W. (1940). The Theory of the Four Monarchies. Opposition History under the Roman Empire. CPh 35, 4-21.

Trieber, C. (1892). Die Idee der vier Weltreiche. Hermes 27, 321-344.

Vlassopoulos, K. (2007). Unthinking the Greek Polis: Ancient Greek History beyond Eurocentrism. Cambridge: Cambridge University Press.

Walbank, F. W. (1957-1979). A Historical Commentary on Polybius. 3 vols. Oxford: Clarendon Press.

Walbank, F. W. (1962). Polemic in Polybius. JRS 52, 1-12.

Yarrow, L. (2006). Historiography at the End of the Republic: Provincial Perspectives on Roman Rule. Oxford: Oxford University Press.

Para citar este artículo:

Vega Rodríguez Héctor A. (2019). Diodoro de Sicilia y la historia universal. Anuario de la Escuela de Historia Virtual 15, 1-26. 